\title{
LONGITUDINAL STUDY FOR THE ASSESSMENT OF THE STRENGTH AT STUDENTS (FEMALE)
}

\author{
Leuciuc Florin Valentin ${ }^{1 *}$ \\ Pricop Gheorghe 2 \\ Grosu Bogdan ${ }^{3}$ \\ Păcuraru Alexandru 4 \\ 1,2,3Ștefan cel Mare University of Suceava, Universității street, 13, 720229, Romania \\ ${ }^{4}$ State University of Physical Education and Sports, 22 Andrei Doga street, Chișinău, \\ MD-2024, Republic of Moldova
}

Keywords: strength, youth, evaluation.

\begin{abstract}
There are various methods of strength development which are based on different working principles and shapes. The research hypothesis was that by applying a weekly strength development program the students will achieve progress with the tests for muscle groups chosen. The research was conducted during the academic years 20132014 (second semester) and 2014-2015 (first semester) and included a total of 32 subjects, girls (2013-2014 - 26, 2014-2015 - 6). For each of the two semesters during the research it was 14 weeks (first and last for evaluations, 12 weeks of the workout program). These differences were particularly visible evidence for deltoids and arms tests, the other two tests values were relatively close (dorsal, chest). The progresses achieved were different, which is why we believe that individual characteristics and composition of groups led to these results.
\end{abstract}

\section{Introduction}

The human body strength lies in its ability to achieve overcoming efforts, maintenance or release in relation to external or internal resistance by contraction of one or more muscles. Analyzing human body strength, we can say that it is the subject of investigations of the physiological and methodological in physical education and sport (Dragnea, Mate-Teodorescu, 2002, p. 356; Raţă, \& Raţă, 2006, p. 34).

There are various methods of strength development which are based on different working principles and shapes. Differences with regard to the working methods used are: load, number of repetitions, number of sets, speed of execution, length of the breaks (Cometti, 2014, p. 3; Waymel \& Choque, 2011,

\footnotetext{
*E-mail: florinl@usv.ro
} 
p. 41). The effects of muscle training occur when working methods respect the following principles: application workload required for each training (session) and successive meetings; increasing work loads and dosage depending on the degree of training (Lee, 2007, p. 45-46; Leuciuc, 2010, p. 9-10).

The test of repetition maximum (1 RM) is a common method to measure muscle strength. It aims to measure the maximum strength of a subject highlighted in one repetition for a specific movement (Leuciuc, 2010, p. 160).

\section{Material and methods}

The research hypothesis was that by applying a weekly strength development program the students will achieve progress with the tests for muscle groups chosen.

The research was conducted during the academic years 2013-2014 (second semester) and 2014-2015 (first semester) and included a total of 32 subjects, girls (2013-2014 - 26, 2014-2015 - 6). For each of the two semesters during the research it was 14 weeks (first and last for evaluations, 12 weeks of the workout program). The program applied during the research was done once a week, during training session is 100 minutes by the application of specific exercises for the muscle groups evaluated, using the load between 30 and $70 \%$ of R.M. (maximum repetition) being performed 6-15 repetitions in 3-4 sets.

The academic program requires weekly from subjects between 6 and 8 hours of practical work, and some of the subjects are engaged in sports activities. In carrying out of the scientific research we used the following methods: method of studying literature, method of control samples and tests, statistical and mathematical method and graphical method.

Method of control samples and tests - targeted selection and application control samples, according to the available material basis for evaluation under maximum strength and strength-resistance of the subjects.

Through the initial and final evaluations was aimed to determine the maximum force and the resistance of the subjects under the following muscles:

- chest - from sitting at the machine with compressed air pushing horizontally movements; the load is gradually increased until it reaches the maximum limit that is capable the subject; maximum result obtained (in kg) it is the maximum performance and it is recorded;

- dorsal - from sitting at the machine with compressed air pushing horizontally movements; the load is gradually increased until it reaches the maximum limit that is capable the subject; maximum result obtained (in kg) it is the maximum performance and it is recorded;

- deltoids - from sitting at the machine with compressed air pushing vertically movements; the load is gradually increased until it reaches the maximum limit that is capable the subject; maximum result obtained (in $\mathrm{kg}$ ) it is the maximum performance and it is recorded;

- arms - the subject must maintain the hang position with outstretched arms; the result obtained is recorded in seconds. 


\section{Results and discussions}

After the testings data was centralized and mathematical statistics was performed by calculating the following parameters: arithmetic mean, maximum, minimum, standard deviation, coefficient of variation.

The results were analyzed according to each period of research (table 1).

Table 1. The results at strength tests applied in research

\begin{tabular}{|c|c|c|c|c|c|c|c|c|}
\hline \multirow[t]{2}{*}{$\begin{array}{c}\text { Statistical } \\
\text { paramether }\end{array}$} & \multicolumn{2}{|c|}{$\begin{array}{c}\text { Muscular } \\
\text { strength - } \\
\text { Deltoids (kg) } \\
\end{array}$} & \multicolumn{2}{|c|}{$\begin{array}{c}\text { Muscular } \\
\text { strength - } \\
\text { Dorsal (kg) } \\
\end{array}$} & \multicolumn{2}{|c|}{$\begin{array}{l}\text { Muscular } \\
\text { strength - } \\
\text { Chest (kg) } \\
\end{array}$} & \multicolumn{2}{|c|}{$\begin{array}{l}\text { Muscular } \\
\text { strength - } \\
\text { Arms (kg) }\end{array}$} \\
\hline & IT & FT & IT & FT & IT & FT & IT & FT \\
\hline \multicolumn{9}{|c|}{ Academic year 2014-2015, n=6 } \\
\hline $\mathbf{X}$ & 27,27 & 30,08 & 45,96 & 48,27 & 38,58 & 40,96 & 52,31 & 61,88 \\
\hline MAX & 45 & 45 & 65 & 60 & 58 & 60 & 103 & 110 \\
\hline MIN & 20 & 20 & 30 & 40 & 25 & 30 & 20 & 31 \\
\hline $\mathbf{S}$ & 5,22 & 5,54 & 8,00 & 6,47 & 6,92 & 6,33 & 21,58 & 21,09 \\
\hline $\mathbf{C V}$ & 19,14 & 18,43 & 17,41 & 13,41 & 17,93 & 15,45 & 41,26 & 34,08 \\
\hline \multicolumn{9}{|c|}{ Academic year 2013-2014, n=26 } \\
\hline $\mathbf{X}$ & 34,00 & 36,00 & 46,33 & 50,50 & 40,67 & 42,17 & 55,17 & 55,00 \\
\hline MAX & 37 & 40 & 55 & 60 & 49 & 50 & 102 & 101 \\
\hline MIN & 32 & 34 & 40 & 45 & 32 & 35 & 30 & 20 \\
\hline $\mathbf{S}$ & 2,00 & 2,19 & 5,89 & 6,53 & 5,85 & 5,64 & 30,22 & 36,60 \\
\hline $\mathbf{C V}$ & 5,88 & 6,09 & 12,71 & 12,94 & 14,39 & 13,37 & 54,77 & 66,54 \\
\hline
\end{tabular}

At the test for shoulder muscles, the subjects who participated in the research in the academic year 2013-2014 were recorded at initial testing an average of $34 \mathrm{~kg}$ (minimum-32, maximum-37) and at the final $36 \mathrm{~kg}$ (minimum34, maxim-40); group homogeneity was higher given the variability coefficient values $(5.88 \% ; 6.09 \%)$, and progress was $5.6 \%$. The working group of the academic year 2014-2015 arithmetic average of initial testing was $27.27 \mathrm{~kg}$ (minimum-20 maximum-45) and at the final $30.08 \mathrm{~kg}$ (minimum-20, maximum45); variability coefficient values were $19.14 \%$, respectively $18.43 \%$ indicating low homogeneity and progress group was 9.3\% (figure 1).

In both groups the upward trend it is between the two tests, which confirmed the effectiveness of the proposed work program and applied. In the second group, the variation coefficient values indicates low homogeneity as both individual test results were set in a wide range of values: $20-45 \mathrm{~kg}$. 


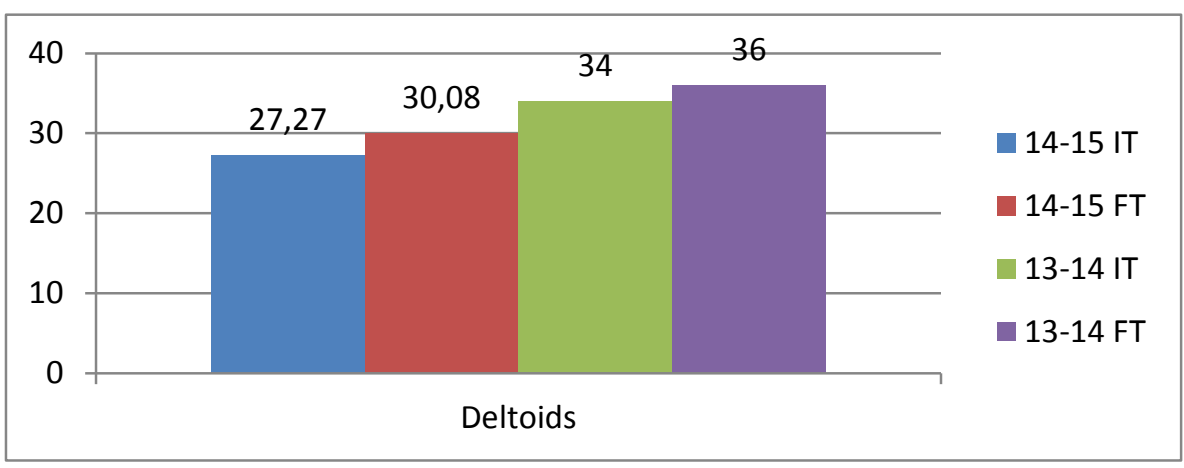

Figure 1. Results for Deltoids test 1 RM (maximum repetition)

For dorsal muscle assessed by the test sitting at the machine with compressed air pushing horizontally movements, the first group (2013-2014) achieved a 8.2\% improvement from $46.33 \mathrm{~kg}$ to $50.5 \mathrm{~kg}$; individual values ranging between 40 and $55 \mathrm{~kg}$ initial testing, ie between 45 and $60 \mathrm{~kg}$ in final testing. In the second group (2014-2015) progress was $4.8 \%$ - from $45.96 \mathrm{~kg}$ to $48.27 \mathrm{~kg}$; individual results were in the range $30-65 \mathrm{~kg}$ at initial test, respectively $40-60 \mathrm{~kg}$ at the final test (figure 2).

At the end of 12 weeks of activity, according to established working program, both groups were in progress, so that the means used to develop the muscles were well chosen and dosed in accordance with the particularities of each group.

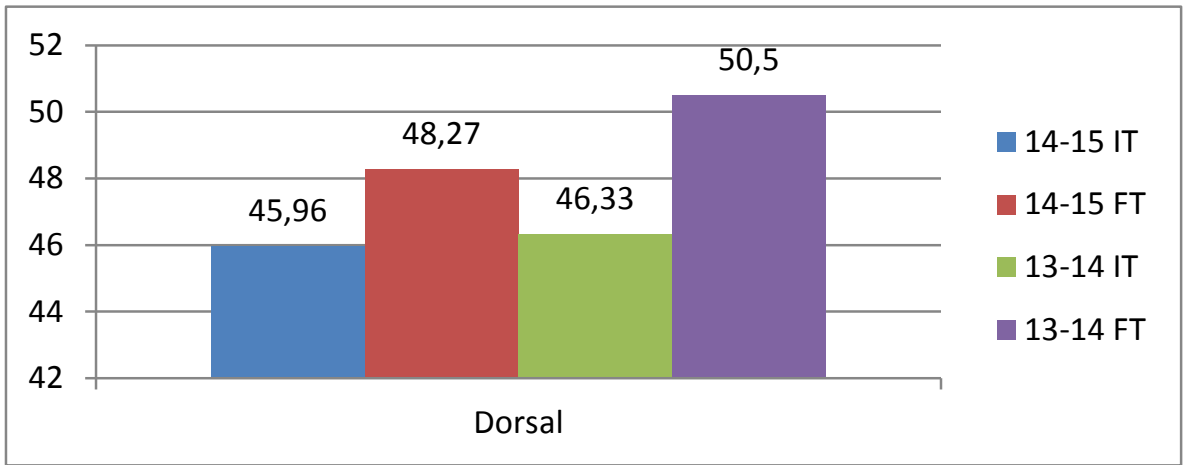

Figure 2. Results for Dorsal test 1 RM (maximum repetition)

For chest and arms muscles we use sample pushed horizontally from sitting at the machine with compressed air, and the first group (2013-2014) was started from an average at initial testing of $40.67 \mathrm{~kg}$ and reached $42.17 \mathrm{~kg}$ at final testing, the progress was $3.6 \%$, and individual results were it the range of $32-50 \mathrm{~kg}$. In the second group (2014-2015) progress was $2.38 \mathrm{~kg}$ (initial testing$38.58 \mathrm{~kg}$, final testing, $40.96 \mathrm{~kg}$ ) or $5.8 \%$ in percentage expression (figure 3). 
It is the third test aimed at evaluating the maximum strength of the subjects, and the results indicate improvement in both groups, but this is the lowest one. Related to this issue, in the future we must consider other means, with the appropriate dosages which to act on the muscle groups targeted by this evidence.

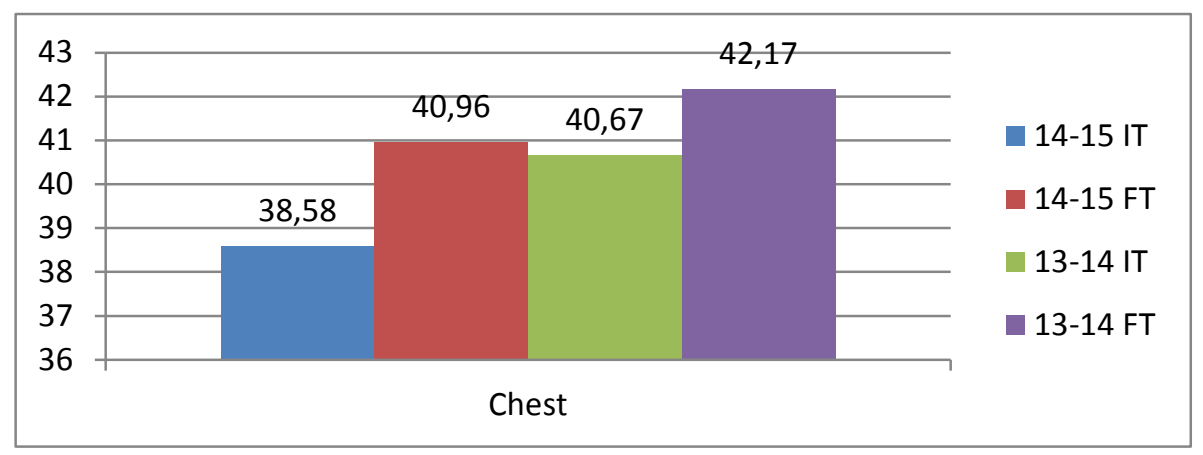

Figure 3. Results for Chest test 1 RM (maximum repetition)

For arms test were obtained the highest values of the coefficient of variation $(34.08 \%$ - 41.26\%), so small groups homogeneity. The first group (2013-2014) was 9.57 seconds progress or 15.4\%, and the second (2014-2015) declined with 0.17 seconds or $0.3 \%$ (figure no. 4).

With this test was evaluated strength and resistance of the muscles of the arms and the individual results were varied, but the first group was found in progress, and the second somewhat weaker, although the means applied were similar. In the future should be considered as applying development methods for strength and resistance to take more in account the particularities of the group to which it applies.

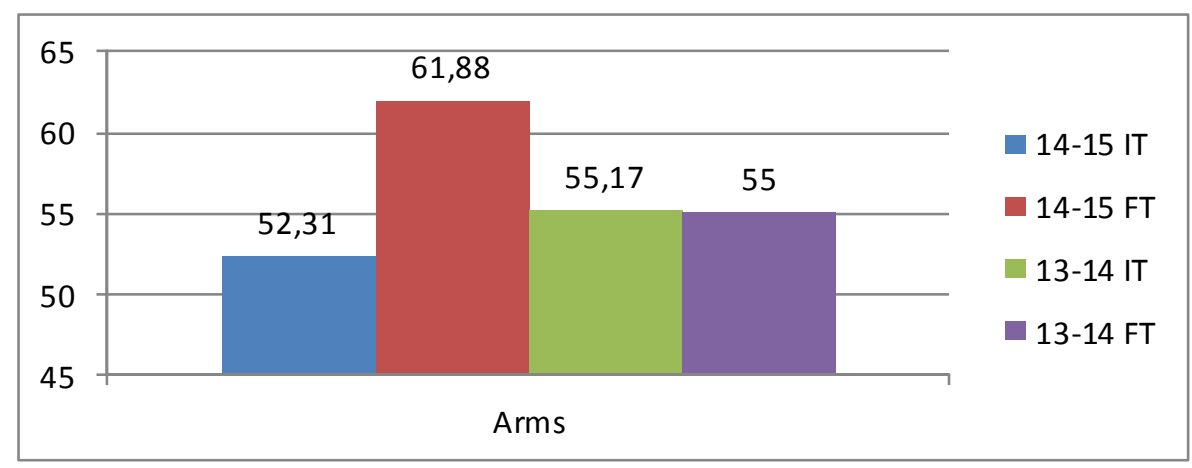

Figure 4. Results for Arms test (maximum repetition)

The progress (in absolute and percentage expression) of the two groups between the two testings are as follows (table no. 2). 
Table 2. Progress obtained in control tests between the two testings

\begin{tabular}{|c|c|c|c|c|c|c|c|c|}
\hline \multirow[t]{2}{*}{$\begin{array}{c}\text { Statistical } \\
\text { paramethers }\end{array}$} & \multicolumn{2}{|c|}{$\begin{array}{c}\text { Muscular } \\
\text { strength - } \\
\text { Deltoids (kg) }\end{array}$} & \multicolumn{2}{|c|}{$\begin{array}{c}\text { Muscular } \\
\text { strength - } \\
\text { Dorsal (kg) }\end{array}$} & \multicolumn{2}{|c|}{$\begin{array}{l}\text { Muscular } \\
\text { strength - } \\
\text { Chest (kg) }\end{array}$} & \multicolumn{2}{|c|}{$\begin{array}{l}\text { Muscular } \\
\text { strength - } \\
\text { Arms (kg) }\end{array}$} \\
\hline & IT & FT & IT & FT & IT & FT & IT & FT \\
\hline \multicolumn{9}{|c|}{ Academic year 2014-2015, n=6 } \\
\hline $\mathbf{X}$ & 27,27 & 30,08 & 45,96 & 48,27 & 38,58 & 40,96 & 52,31 & 61,88 \\
\hline Progress & \multicolumn{2}{|c|}{2,79} & \multicolumn{2}{|c|}{2,31} & \multicolumn{2}{|c|}{2,38} & \multicolumn{2}{|c|}{9,57} \\
\hline $\begin{array}{l}\text { Progress } \\
(\%)\end{array}$ & \multicolumn{2}{|c|}{9,3} & \multicolumn{2}{|c|}{4,8} & \multicolumn{2}{|c|}{5,8} & \multicolumn{2}{|c|}{15,4} \\
\hline \multicolumn{9}{|c|}{ Academic year 2013-2014, n=26 } \\
\hline $\mathbf{X}$ & 34,00 & 36,00 & 46,33 & 50,50 & 40,67 & 42,17 & 55,17 & 55,00 \\
\hline Progress & \multicolumn{2}{|c|}{2,00} & \multicolumn{2}{|c|}{4,17} & \multicolumn{2}{|c|}{1,50} & \multicolumn{2}{|c|}{$-0,17$} \\
\hline $\begin{array}{l}\text { Progress } \\
(\%)\end{array}$ & \multicolumn{2}{|c|}{5,6} & \multicolumn{2}{|c|}{8,2} & \multicolumn{2}{|c|}{3,6} & \multicolumn{2}{|c|}{$-0,3$} \\
\hline
\end{tabular}

\section{Conclusions}

Although both groups to apply the same training program in two different periods, there are certain differences due to their individual subjects. These differences were particularly visible evidence for deltoids and arms muscles, the other two tests values were relatively close (dorsal, chest).

The progresses achieved were different, which is why we believe that individual characteristics and composition of groups led to these results.

The results obtained and the progress of each group indicates that a single training session performed weekly for the development of the subjects effects maximum force there to a minimum (2-10\%), so for the following studies should be increased the number of weekly meetings to see what connection there is between them and the progress that will be achieved.

According to the results we can say that the research hypothesis was confirmed, but the effect is minimum with one workout weekly regarding to the development of the students' strength.

\section{References}

1. DRAGNEA, A., MATE-TEODORESCU, S., M. (2002). Teoria sportului, Bucureşti: FEST, p. 356.

2. LEE E. B., (2007). Strength Training, Human Kinetics, Champaign, pp. 45-46.

3. LEUCIUC F.V. (2010). Musculaţie, Suceava: Editura Universităţii Ştefan cel Mare, pp. 9,10, 160.

4. RAŢĂ, G., RAŢĂ, C.B., (2006). Aptitudinile în activitatea motrică, editura Edu-Sport, Bacău

5. WAYMEL T., CHOQUE, J., (2011). Etirement \& renforcement musculaire (sante, forme, preparation physigue), Paris: Editions Amphora, France, p. 41.

6. http://expertise-performance.u-bourgogne.fr/pdf/mecanismes_force_fin.pdf, COMETTI G., Les mecanismes de la force, 25.09.2014, p. 3. 


\title{
STUDIU LONGITUDINAL PRIVIND EVALUAREA FORŢEI LA STUDENŢI (FEMININ)
}

\author{
Leuciuc Florin Valentin ${ }^{1}$ \\ Pricop Gheorghe 2 \\ Grosu Bogdan ${ }^{3}$ \\ Păcuraru Alexandru 4 \\ 1,2,3 Universitatea Ștefan cel Mare, Suceava, Str. Universității 13, 720229, Romania \\ ${ }^{4}$ Universitatea de Stat pentru Educație Fizică și Sport, Chișinău, Str. 22 Andrei Doga, \\ MD-2024, Republica Moldova
}

Cuvinte cheie: forţă, tineri, evaluare.

\section{Rezumat}

Există diferite metode de musculaţie care au la bază principii şi forme diferite de lucru. Ipoteza cercetării a fost că prin aplicarea unui program săptămânal pentru dezvoltarea forţei la studente vom obţine progrese prin aplicarea testului o repetare maximă la grupele musculare alese. Cercetarea s-a desfăşurat în perioada anilor universitari 20132014 (semestrul II) şi 2014-2015 (semestrul I) şi a cuprins un număr de 32 de subiecţi, băieţi (2013-2014 - 26, 2014-2015 - 6). Pentru fiecare din cele două semestre durata cercetării a fost de 14 săptămâni (prima şi ultima pentru evaluări, 12 săptămâni de aplicare programului de lucru). Aceste diferenţe au fost vizibile în special la probele deltoizi şi braţe, la celelate două probe valorile au fost relativ apropiate (dorsali, piept). Progresele obţinute au fost diferite, fapt pentru care considerăm că particularităţile individuale şi componența grupelor au condus la aceste rezultate.

\section{Introducere}

Forţa organismului uman constă în capacitatea de a realiza eforturi de învingere, menţinere sau cedare în raport cu o rezistenţă externă sau internă, prin contracţia uneia sau mai multor grupe musculare. Analizând forţa organismului uman, putem spune că ea constituie obiectul de studiu al investigaţiilor fiziologice şi metodologice din domeniul educaţie fizică şi sport (Dragnea, Mate-Teodorescu, 2002, p. 356; Raţă \& Raţă, 2006, p. 34).

Există diferite metode de musculaţie care au la bază principii şi forme diferite de lucru. Diferenţieri în ceea ce priveşte metodele de lucru utilizate sunt: încărcătura, numărul de repetări, numărul de serii, viteza de execuţie, durata pauzelor (Cometti, 2014, p. 3; Waymel \& Choque, 2011, p. 41).

Efectele pregătirii musculare apar atunci când metodele de lucru respectă următoarele principii: aplicarea volumului de lucru necesar pentru fiecare antrenament (şedinţă), respectiv în şedinţe succesive; creşterea încărcăturii şi a dozării lucrului în funcţie de gradul de antrenament (Lee, 2007, p. 45-46; Leuciuc, 2010, p. 9-10). 
Testul unei repetări maxime (1 RM) este o metodă uzuală pentru a măsura forţa musculară. Ea are ca scop de a măsura forţa maximă a unui subiect evidenţiată într-o singură repetare pentru o mişcare specifică (Leuciuc, 2010, p. 160).

\section{Material şi metode}

Ipoteza cercetării presupune că folosirea unui program săptămânal pentru dezvoltarea forţei la studente va conduce la obţinerea de progrese prin aplicarea testului o repetare maximă la grupele musculare alese.

Cercetarea s-a desfăşurat în perioada anilor universitari 2013-2014 (semestrul II) şi 2014-2015 (semestrul I) şi a cuprins un număr de 32 de subiecţi (feminin) (2013-2014: 26, 2014-2015: 6). Pentru fiecare din cele două semestre durata cercetării a fost de 14 săptămâni (prima şi ultima pentru evaluări, 12 săptămâni de aplicare programului de lucru). Programul aplicat pe perioada cercetării s-a făcut o dată pe săptămână, durata şedinţei de pregătire fiind de 100 de minute prin aplicarea de exerciții specifice pentru grupele musculare evaluate, fiind utilizate încărcăturii cuprinse între 30 și 70\% din R.M. (repetare maximă), fiind executate 6-15 repetări în 3-4 serii.

Programul academic al subiecţilor prevede săptămânal între 6 şi 8 ore de activităţi practice, iar o parte din subiecţi sunt implicaţi în activităţi sportive de performanţă.

În realizarea demersului științific am utilizat următoarele metode de cercetare: metoda studierii literaturii de specialitate, metoda probelor şi testelor, metoda statistico-matematică și cea grafică.

Metoda probelor şi testelor de control - a vizat alegerea și aplicarea probelor de control, în concordanță cu baza materială avută la dispoziție, pentru evaluarea forței maxime și în regim de rezistență a subiecților.

Prin intermediul evaluărilor iniţială şi finală s-a vizat determinarea forţei maxime şi a celei în regim de rezistenţă a subiecţilor la următoarele grupe musculare:

- pectorali - din aşezat la aparatul cu aer comprimat subiecții execută mișcări de împingere în plan orizontal; încărcătura este crescută treptat până se atinge limita maximă de care este capabil executantul; rezultatul maxim obținut (în kg) este consemnat ca performanță maximă la data evaluării;

- dorsali - din aşezat la aparatul cu aer comprimat se execută mișcări de tragere în plan orizontal; încărcătura este crescută treptat până se atinge limita maximă de care este capabil executantul; rezultatul maxim obținut (în kg) este consemnat ca performanță maximă la data evaluării;

- deltoizi - din aşezat la aparatul cu aer comprimat se execută mișcări de împingere în plan vertical; încărcătura este crescută treptat până se atinge limita maximă de care este capabil executantul; rezultatul maxim obținut (în kg) este consemnat ca performanță maximă la data evaluării;

- braţe - executantul trebuie să menţină poziția atârnat la bară cu brațele întinse; timpul obținut se consemnează în secunde. 


\section{Rezultate şi discuţii}

După testări datele au fost centralizate şi a fost realizată statistica prin calcularea următorilor parametrii: medie aritmetică, valoare maximă, valoare minimă, abatere standard, coeficient de variabilitate.

Rezultatele obţinute au fost analizate pentru fiecare perioadă a cercetării (tabelul 1).

Tabelul 1. Rezultatele obţinute la testele de forţă aplicate

\begin{tabular}{|c|c|c|c|c|c|c|c|c|}
\hline \multirow[t]{2}{*}{$\begin{array}{c}\text { Parametrii } \\
\text { statistici }\end{array}$} & \multicolumn{2}{|c|}{$\begin{array}{c}\text { Forţă } \\
\text { musculară - } \\
\text { Deltoizi (kg) }\end{array}$} & \multicolumn{2}{|c|}{$\begin{array}{c}\text { Forţă } \\
\text { musculară - } \\
\text { Dorsali (kg) } \\
\end{array}$} & \multicolumn{2}{|c|}{$\begin{array}{c}\text { Forţă } \\
\text { musculară - } \\
\text { Pectorali (kg) }\end{array}$} & \multicolumn{2}{|c|}{$\begin{array}{c}\text { Forţă } \\
\text { musculară - } \\
\text { Braţe kg) } \\
\end{array}$} \\
\hline & IT & FT & IT & FT & IT & FT & IT & FT \\
\hline \multicolumn{9}{|c|}{ Anul universitar 2014-2015, $n=6$} \\
\hline $\mathbf{X}$ & 27,27 & 30,08 & 45,96 & 48,27 & 38,58 & 40,96 & 52,31 & 61,88 \\
\hline MAX & 45 & 45 & 65 & 60 & 58 & 60 & 103 & 110 \\
\hline MIN & 20 & 20 & 30 & 40 & 25 & 30 & 20 & 31 \\
\hline $\mathbf{S}$ & 5,22 & 5,54 & 8,00 & 6,47 & 6,92 & 6,33 & 21,58 & 21,09 \\
\hline $\mathbf{C V}$ & 19,14 & 18,43 & 17,41 & 13,41 & 17,93 & 15,45 & 41,26 & 34,08 \\
\hline \multicolumn{9}{|c|}{ Anul universitar 2013-2014, $\mathrm{n}=26$} \\
\hline $\mathbf{X}$ & 34,00 & 36,00 & 46,33 & 50,50 & 40,67 & 42,17 & 55,17 & 55,00 \\
\hline MAX & 37 & 40 & 55 & 60 & 49 & 50 & 102 & 101 \\
\hline MIN & 32 & 34 & 40 & 45 & 32 & 35 & 30 & 20 \\
\hline $\mathbf{S}$ & 2,00 & 2,19 & 5,89 & 6,53 & 5,85 & 5,64 & 30,22 & 36,60 \\
\hline $\mathbf{C V}$ & 5,88 & 6,09 & 12,71 & 12,94 & 14,39 & 13,37 & 54,77 & 66,54 \\
\hline
\end{tabular}

La testul pentru aprecierea forţei musculaturii umerilor, subiecţii care au participat la cercetare în anul universitar 2013-2014 au înregistrat la testarea iniţială o medie de $34 \mathrm{~kg}$ (minim-32, maxim-37), iar la cea finală $36 \mathrm{~kg}$ (minim34, maxim-40); omogenitatea grupului a fost mare prin prisma valorilor coeficientului de variabilitate (5,88\%; 6,09\%), iar progresul a fost de 5,6\%.

La grupa de lucru din anul universitar 2014-2015 media aritmetică a testării iniţiale a fost de $27,27 \mathrm{~kg}$ (minim-20, maxim-45), iar la cea finală de $30,08 \mathrm{~kg}$ (minim-20 kg, maxim $45 \mathrm{~kg}$ ); valorile coeficientului de variabilitate au fost de $19,14 \%$, respectiv $18,43 \%$ ceea ce indică omogenitate mică, iar progresul grupei a fost de $9,3 \%$ (fig. 1 ).

La ambele grupe se observă tendința ascendentă între cele două testări, fapt care confirmă eficiența programului de lucru propus și aplicat. La a doua grupă valorile coeficientului de variabilitate indică omogenitate mică deoarece la ambele testări rezultatele individuale s-au situat într-o plajă largă de valori: $20-45 \mathrm{~kg}$. 


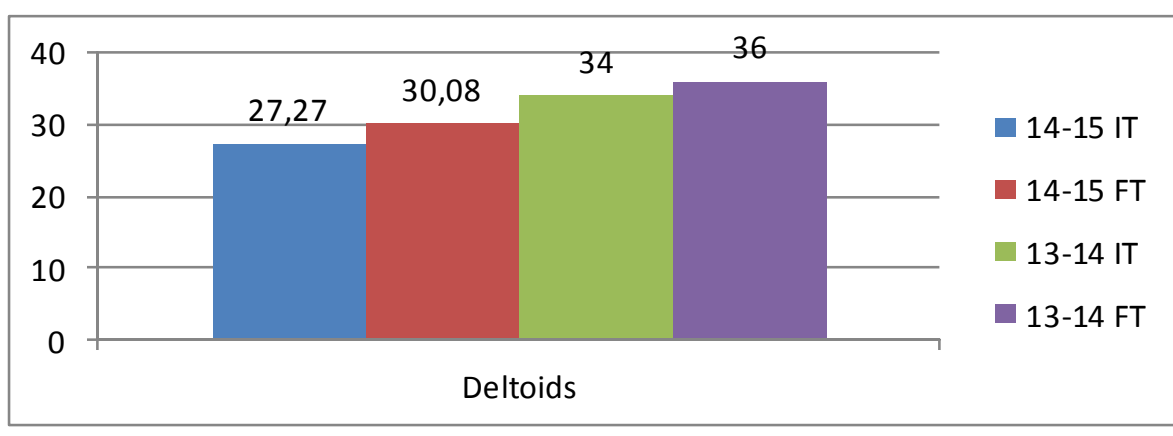

Figura 1. Rezultate pentru testul 1 RM (repetare maximă) deltoizi

Pentru musculatura dorsală, apreciată prin proba tras din aşezat la aparatul cu aer comprimat, prima grupa (2013-2014) a obţinut un progres de 8,2\% de la 46,33 kg la 50,5 kg; valorile individuale variind între 40 şi $55 \mathrm{~kg}$ la testarea iniţială, respectiv între 45 şi $60 \mathrm{~kg}$ la testarea finală. La cea de a doua grupă (2014-2015) progresul a fost de 4,8\% - de la 45,96 kg la 48,27 kg; rezultatele individuale au fost în intervalul 30-65 kg pentru prima grupă, respectiv 40-60 kg la cea de a doua grupă (figura 2).

La finalul celor 12 săptămâni de activitate, conform programului de lucru stabilit, ambele grupe s-au aflat în progres, astfel că mijloacele utilizate pentru dezvoltarea acestei grupe musculare au fost bine alese și dozate în concordanță cu particularitățile fiecărui grup.

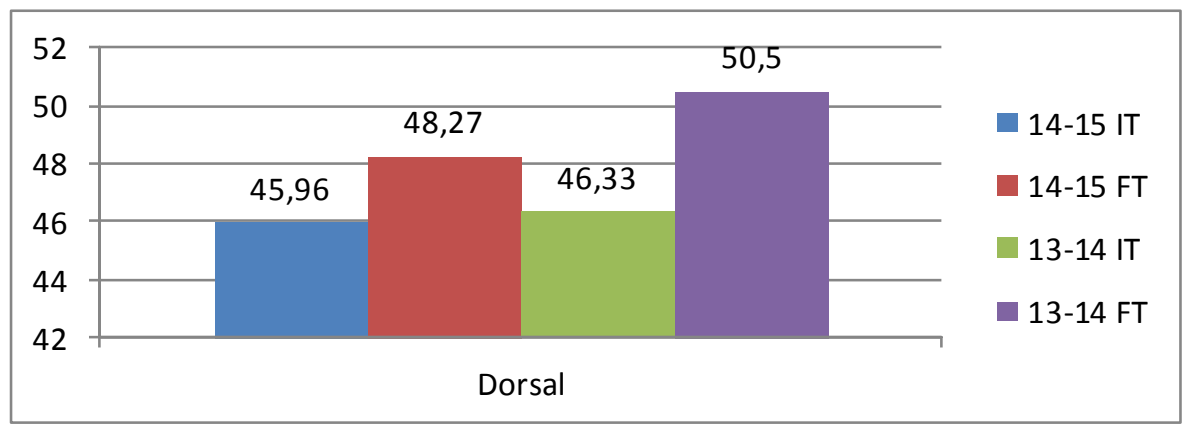

Figura 2. Rezultate pentru testul 1 RM (repetare maximă) dorsali

Pentru musculatura pieptului și brațelor am utilizat proba împins orizontal din aşezat la aparatul cu aer comprimat, iar la prima grupă (2013-2014) s-a pornit de la o medie, la testarea iniţială, de $40,67 \mathrm{~kg}$ şi s-a ajuns la testarea finală la 42,17 kg, progresul fiind de 3,6\%, iar rezultatele individuale au fost în intervalul 32-50 kg. La cea de a doua grupă (2014-2015) progresul a fost de 2,38 $\mathrm{kg}$ (testare iniţială-38,58 kg, testare finală-40,96 kg) sau 5,8\% în exprimare procentuală (figura nr. 3).

Este cea de a treia probă care a vizat evaluarea forței maxime a subiecților, iar rezultatele obținute indică progres la ambele grupe, însă acesta este cel mai mic. În acest sens trebuie ca pe viitor să se aibă în vedere și alte mijloace, cu 
dozările corespunzătoare, prin care să se acționeze asupra grupelor musculare vizate de această probă.

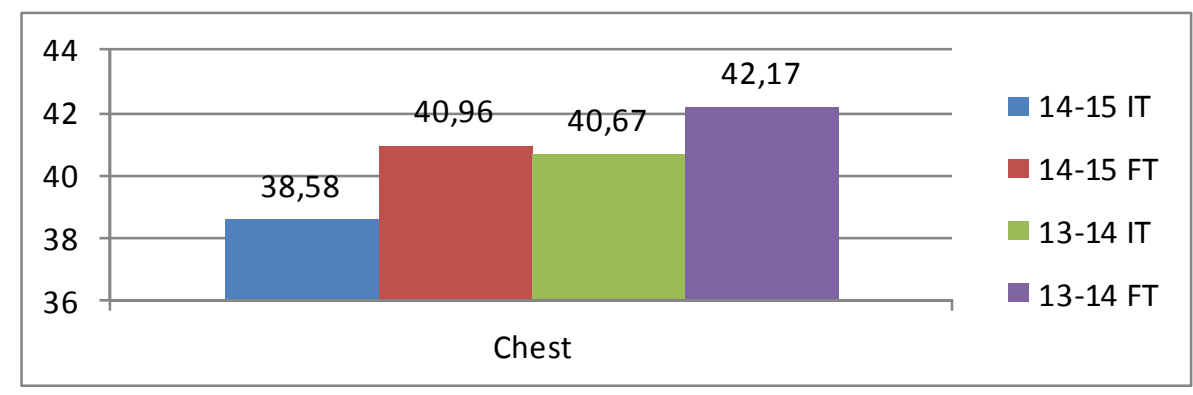

Figura 3. Rezultate pentru testul 1 RM (repetare maximă) pectorali

La menţinere în atârnat s-au obţinut cele mai mari valori pentru coeficientul de variabilitate (34,08\%- 41,26\%), deci şi omogenitate mică a grupelor. La prima grupa (2013-2014) progresul a fost de 9,57 secunde sau 15,4\%, iar la cea de a doua (2014-2015) s-a înregistrat un regres de 0,17 secunde sau $0,3 \%$ (figura 4 ).

Prin intermediul acestei probe s-a evaluat forța în regim de rezistență a musculaturii brațelor, iar rezultatele individuale au fost foarte variate, însă prima grupă s-a aflat în progres, iar cea de a doua în uşor regres, deși mijloacele aplicate au fost similare. Pe viitor trebuie avut în vedere ca prin aplicarea metodelor de dezvoltare a forței în regim de rezistență să se țină cont mai mult de particularitățile grupului la care se aplică.

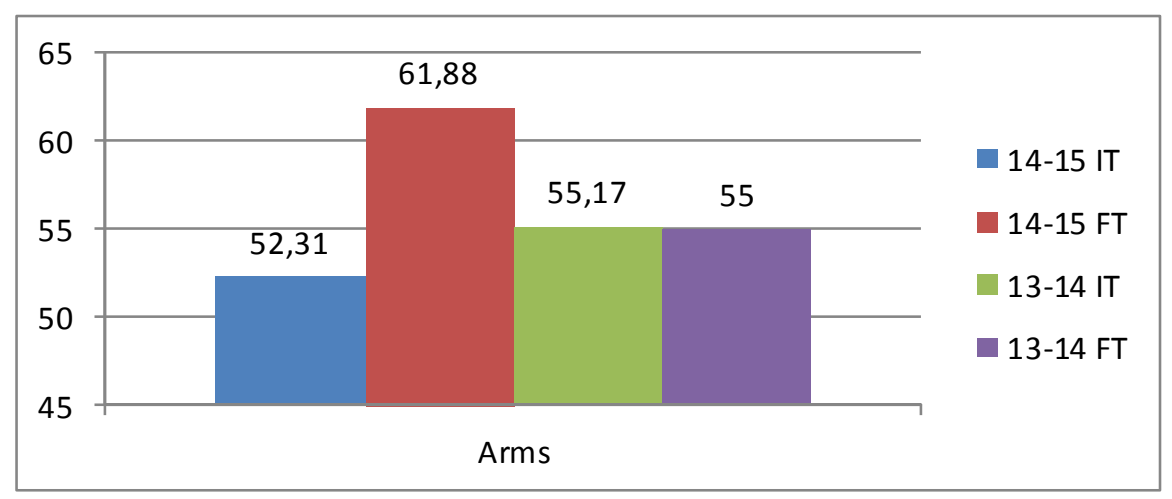

Figura 4. Rezultate pentru testul 1 RM (repetare maximă) braţe

Progresele obţinute (în valoare absolută şi în exprimare procentuală) de cele două grupe, între cele două testări, la probele de control aplicate sunt prezentate în continuare (tabelul 2). 
Tabelul 2. Progresele obţinute la probele de control între cele două testări

\begin{tabular}{|c|c|c|c|c|c|c|c|c|}
\hline \multirow[t]{2}{*}{$\begin{array}{l}\text { Parametrii } \\
\text { statistici }\end{array}$} & \multicolumn{2}{|c|}{$\begin{array}{c}\text { Forță } \\
\text { musculară - } \\
\text { Deltoizi (kg) }\end{array}$} & \multicolumn{2}{|c|}{$\begin{array}{c}\text { Forţă musculară } \\
\text { - Dorsali (kg) }\end{array}$} & \multicolumn{2}{|c|}{$\begin{array}{l}\text { Forță musculară - } \\
\text { Pectorali (kg) }\end{array}$} & \multicolumn{2}{|c|}{$\begin{array}{c}\text { Forţă } \\
\text { musculară - } \\
\text { Brațe kg) }\end{array}$} \\
\hline & IT & FT & IT & FT & IT & FT & IT & FT \\
\hline \multicolumn{9}{|c|}{ An universitar 2014-2015, n=33 } \\
\hline $\mathbf{X}$ & 27,27 & 30,08 & 45,96 & 48,27 & 38,58 & 40,96 & 52,31 & 61,88 \\
\hline Progres & \multicolumn{2}{|c|}{2,79} & \multicolumn{2}{|c|}{2,31} & \multicolumn{2}{|c|}{2,38} & \multicolumn{2}{|c|}{9,57} \\
\hline $\begin{array}{l}\text { Progres } \\
\text { (\%) }\end{array}$ & \multicolumn{2}{|c|}{9,3} & \multicolumn{2}{|c|}{4,8} & \multicolumn{2}{|c|}{5,8} & \multicolumn{2}{|c|}{15,4} \\
\hline \multicolumn{9}{|c|}{ An universitar 2013-2014, n=25 } \\
\hline $\bar{X}$ & 34,00 & 36,00 & 46,33 & 50,50 & 40,67 & 42,17 & 55,17 & 55,00 \\
\hline Progres & \multicolumn{2}{|c|}{2,00} & \multicolumn{2}{|c|}{4,17} & \multicolumn{2}{|c|}{1,50} & \multicolumn{2}{|c|}{$-0,17$} \\
\hline $\begin{array}{l}\text { Progres } \\
(\%)\end{array}$ & \multicolumn{2}{|c|}{5,6} & \multicolumn{2}{|c|}{8,2} & \multicolumn{2}{|c|}{3,6} & \multicolumn{2}{|c|}{$-0,3$} \\
\hline
\end{tabular}

\section{Concluzii}

Deşi la ambele grupe s-a aplicat acelaşi program de pregătire în două perioada diferite, există anumite diferenţe datorate particularităţilor individuale ale subiecţilor. Aceste diferenţe au fost vizibile în special la grupele musculare deltoizi şi braţe, iar pentru celelate două grupe musculare valorile au fost relativ apropiate (dorsali, piept).

Progresele obţinute au fost diferite, fapt pentru care considerăm că particularităţile individuale şi componenţa grupelor au condus la aceste rezultate.

Rezultatele obţinute, precum şi progresele fiecărei grupe indică faptul că printr-o singură şedinţă de pregătire efectuată săptămânal în scopul dezvoltării forţei maxime a subiecţilor efectele există la un nivel minim (2-10\%), astfel că pentru următoarele studii ar trebui crescut numărul de şedinţe săptămânale pentru a vedea ce legătură există între acestea şi progresele ce se vor obţine.

Prin prisma rezultatelor obținute putem afirma că ipoteza cercetării a fost confirmată, însă efectul unei sigure ședințe efectuate săptămânal este minim în ceea ce privește dezvoltarea forței la studente. 